\title{
DER WEG \\ ZUR MEISTERSCHAFT
}

ANLEITUNG ZUR MUSTERHAFTEN FÜHRUNG VON SCHACHPARTIEN

AUF NEUER GRUNDLAGE

VON

F. GUTMAYER

VIERTE, VOLLIG UMGEARBEITETE,

VERBESSERTE AUFLAGE

MIT EINEM TITELBILD

7. ABBILDUNGEN IM TEXT UND VIELEN DIAGRAMMEN

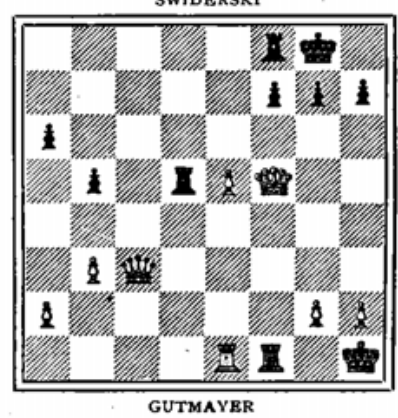

WEISS ZIEHT UND GEWINNT

BERLIN UND LEIPZIG 1923

VEREINIGUNG WISSENSCHAFTLICHER VERLEGER

WALTER DE GRUYTER \& CO.

VORMALS G.J. GÖSCHEN'SCHE VERLAGSHANDLUNG :: J. GUTTENTAG, VERLAGSBUCHHANDLUNG :: GEORG REIMER :: KARL J. TRÜBNER :: VEIT \& COMP. 
Alle Rechte, einschließlich des Ubersetzungsrechts, vorbehalten

Druck von Metzger \& Wittig in Leipzig. 
Ge wid met

verehrend und bew undernd

dem $M$ eister aller Meister,

dem Könige aller Schachkönige

dem amerikanischen Schachheros

\section{PA U L M R P H Y}

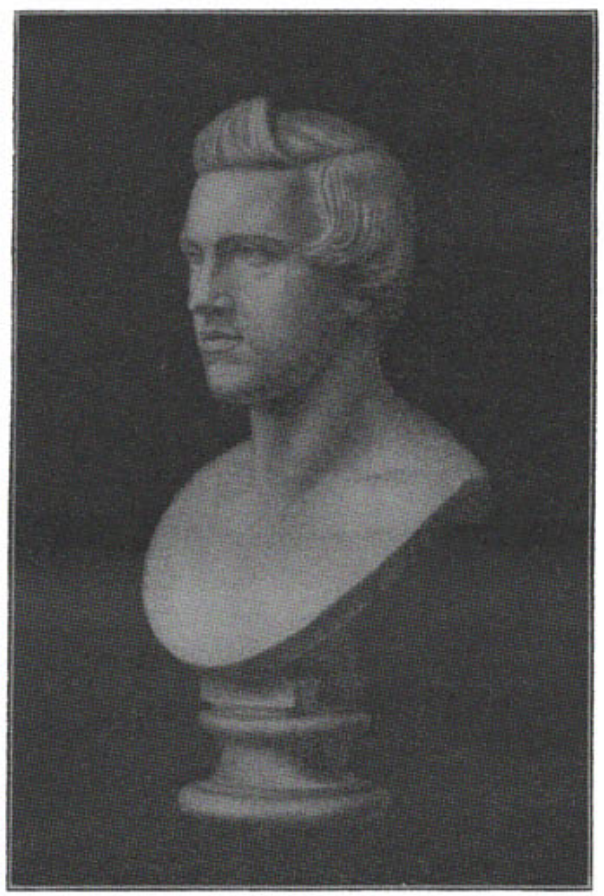

Es wird die Spur von deinen Erdentagen nicht in Äonen untergehen.

Goethe. 
